\title{
CARACTERIZANDO OS TEMAS TRANSVERSAIS E INCENTIVANDO SUA UTILIZAÇÃO NAS AULAS DE MATEMÁTICA
}

DUARTE, Paulo César Xavier ${ }^{1}$

RESUMO: Este artigo tem como objetivo caracterizar os Temas Transversais, a saber, Ética, Orientação Sexual, Meio Ambiente, Saúde, Pluralidade Cultural, Trabalho e Consumo e Temas Locais, bem como incentivar o uso dos mesmos nas aulas de Matemática. Esta pesquisa foi idealizada com um grupo de alunos, Oliveira, V.D, Reis, S.P.e Silva, C.A.S., de Licenciatura em Matemática Plena da Universidade do Vale do Sapucaí- UNIVÁS, situada em Pouso Alegre- MG, com o objetivo de produzirem uma pesquisa baseada na transversalidade. Isto posto, foi realizada uma pesquisa qualitativa, considerando-se como principais referenciais teóricos as Leis de Diretrizes e Bases da Educação Nacional - LDB (1996), os Parâmetros Curriculares Nacionais - PCN (1998) e diversas obras de teóricos da educação.

Palavras chave: Temas transversais. Matemática. LDB. PCN.

SUMMARY: The Temas Transversais are characterized in this article - such as Ethics, Sexual Orientation, Environment, Health, Cultural Plurarity, Work and Consumerism, Local Themes as well as motivate their uses in the math classes. This research was idealized with a group of students, Oliveira, V.D., Reis, S.P.; Silva, C.A.S., of the Full Degree in Mathematics Course from Universidade do Vale do Sapucaí - UNIVAS, located in Pouso Alegre - MG, with the aim to accomplish a final paper based on transversality. The research was done through literature and it is considered as the main theoretical referential the Leis de Diretrizes e Bases da Educação Nacional - LDB (1996), the Parâmetros Curriculares Nacionais - PCN (1998) and several works of educational theorists.

Keywords: Temas transversais. Mathematics. LDB. PCN.

\section{INTRODUÇÃO}

A inclusão dos temas transversais na disciplina de Matemática apoiada em uma metodologia de ensino, auxilia na formação de um aluno crítico, sendo importante também na construção de um currículo que permita o desenvolvimento de competências e na melhoria do ensino-aprendizagem (GROENWALD; BERNDT, 2005,p.1).

Isso posto, convém ressaltar que nos dias atuais, além de trabalhar o conteúdo de sua disciplina, o professor de Matemática deve se preocupar com a formação do cidadão para o exercício da cidadania. (OLIVEIRA; REIS; SILVA, 2009).

Desse modo, não basta apenas uma educação voltada para a apreensão de conceitos. É necessário que a educação também atue como formadora de cidadãos. Segundo Prestini (2005),

\footnotetext{
${ }^{1}$ Doutorando e Mestre em Educação Matemática pela UNESP , de Rio Claro-SP. Professor Assistente do Departamento de Matemática da UNIVÁS- Universidade do Vale do Sapucaí- Pouso Alegre- MG. 
[...] a formação do cidadão é um dos principais objetivos da educação de hoje, que busca promover a pessoa como um todo, pois somente a construção de conhecimentos e desenvolvimento de habilidades, critérios básicos, que em parte sempre acompanharam os princípios da educação no Brasil, não são vistos como suficientes, exigindo do sistema educacional uma formação voltada para a construção da cidadania (2005, p. 9).

E a lei de Diretrizes e Bases da Educação Nacional- LDB (1996) enfatiza em seu artigo $2^{\circ}$, que

[...] a educação, dever da família e do Estado, inspirada nos princípios de liberdade e nos ideais de solidariedade humana, tem por finalidade o pleno desenvolvimento do educando, seu preparo para o exercício da cidadania e sua qualificação para o trabalho.

E esse artigo nos remete a Duarte, que nos diz que,

Cidadão atuante, é um indivíduo que planeja, reflete e age, sempre com conceitos de moral e ética, com a finalidade de obter resultados satisfatórios para um bom desempenho de suas atividades. (2010, p.31).

Porém, IMENES (1991), ressalta e critica a visão linear do currículo de matemática que está pautado num modelo platônico, no qual os pré-requisitos são fundamentais para o desenvolvimento de certos conteúdos.

E em consonância com isso, Fabro nos diz que

[...] isso ocorre por que "na escola as operações possíveis de viabilizar o raciocínio conclusivo têm sido, muitas vezes, aprendidas de forma algorítmica e fragmentada, aplicadas e cobradas de forma imediatista, fora de um contexto significativo" (apud GROENWALD; BERNDT, 2001, p.2).

Assim, a escola necessita "enriquecer as estruturas de pensamento, [dos alunos] de modo que, dispondo de um rol maior de possibilidades, o aluno possa optar, no futuro, por soluções mais eficazes" (CARVALHO apud GROENWALD; BERNDT, 2005,p.1).

Outra dificuldade encontrada pela escola "pode ser atribuída ao fato dos alunos não encontrarem nas técnicas que a escola ensina uma relação com o mecanismo mental que utilizam no seu dia-a-dia" (SEED, 1992, p.67).

Nesse sentido, Pietropaolo ressalta que

[...] ao tratar da formação dos professores que vão ensinar Matemática destaca dentre os aspectos que possam abarcar toda a gama de conhecimentos, atitudes e valores necessários e passíveis de serem construídos e apropriados pelos professores, a inserção cultural, social e política do mesmo no mundo e também que seus conhecimentos extrapolem significativamente as fronteiras de sua disciplina. Ainda, nessa mesma perspectiva, em relação ao conhecimento específico, espera-se que o professor tenha domínio profundo e amplo dos conteúdos que provavelmente irá ensinar, e também que estabeleça as conexões e inter-relações 
entre as diferentes temáticas da área de conhecimento, no nosso caso a matemática (apud PRESTINI, 2005, p.1).

Com o compromisso de trabalhar com estas questões de urgência social numa perspectiva de transversalidade, os professores de cada área trazem como necessidade um estudo sobre tais questões, o que pode ser feito inicialmente por meio de leitura dos documentos de Temas Transversais que fazem parte dos Parâmetros Curriculares Nacionais, e de sua discussão no âmbito da escola, pois uma vez que é o tratamento dado aos conteúdos de todas as áreas que possibilita ao aluno a compreensão destas questões, o que inclui a aprendizagem de conceitos, procedimentos e o desenvolvimento de atitudes (BRASIL, 1998).

Sendo assim, esse artigo procura através de uma pesquisa qualitativa, abordar os temas transversais, tendo em vista a seguinte questão: como são caracterizados os temas transversais?

E em consonância com esta questão, este artigo também procura incentivar o uso dos temas transversais nas aulas de Matemática, através de suas definições e caracterizações.

\section{REFERENCIAL TEÓRICO}

Os temas transversais podem ser abordados nas aulas de Matemática por meio de situações-problema e trabalhados individualmente ou em grupos, podendo assim, enriquecer as atividades do professor seguindo as orientações da Lei de Diretrizes e Bases da Educação Nacional- LDB (1996) e dos Parâmetros Curriculares Nacionais- PCN (1998).

Isto posto, passaremos a caracterização dos temas transversais.

\section{$1.1 \quad$ ÉTICA}

Viver numa sociedade onde conviver com outros homens exige pensar em como agir perante os outros é o que permeia a Moral e a Ética.

Isso nos remete ao dicionário Houaiss (2009, p.847), que nos diz que,

[...] a palavra Ética é um conjunto de regras e preceitos de ordem valorativa e moral de um indivíduo, de um grupo social ou de uma sociedade. Parte da filosofia responsável pela investigação que motiva, distorcem, disciplinam ou orientam o comportamento humano, refletindo especialmente a respeito da essência das normas, valores, prescrições e exortações presentes em qualquer realidade social.

Assim, ética pode assumir variados sentidos. Pode significar Filosofia da Moral, um pensamento reflexivo sobre os valores e as normas que dirigem os comportamentos humanos. 
Em outra análise, ética pode referir-se a um conjunto de princípios e normas que um grupo estabelece para seu exercício profissional (por exemplo, os códigos de ética dos médicos, dos advogados, dos psicólogos, etc.) (BRASIL, 1998).

O tema Ética encontra-se na escola, em primeiro lugar - nas próprias relações entre os indivíduos que constituem essa instituição: alunos, professores, funcionários e pais. Em segundo lugar, encontra-se nas disciplinas do currículo, uma vez que o conhecimento não é neutro e nem resistente a valores de toda espécie. Enfim, encontra-se nos demais Temas Transversais, em que, de uma forma ou de outra, tratam de valores e normas e que trazem como objetivo maior da escola um comprometimento com a formação para a cidadania, trazendo como proposta a realização de um trabalho que possibilite o desenvolvimento da autonomia moral, condição para a reflexão ética. (BRASIL, 1998).

Assim, é essencial destacarmos nas aulas de Matemática temas do quotidiano disponíveis nas revistas semanais e mensais, nos jornais diários e livros que privilegiem aspectos da ética e os utilizarmos em nossas práticas pedagógicas, visando a formação do cidadão para o exercício da cidadania. (OLIVEIRA; REIS; SILVA, 2009, p.56).

\title{
1.2 ORIENTAÇÃO SEXUAL
}

Esse tema busca analisar a sexualidade como um assunto essencial à vida e à saúde e que se expressa no ser humano do nascimento até a morte. Abordando sua importância na prevenção de doenças e no exercício da sexualidade com responsabilidade, colaborando para superação dos preconceitos (BRASIL, 1998).

Segundo o PCN de Orientação Sexual:

\begin{abstract}
Relacionado-se com o direito ao prazer e ao exercício da sexualidade com responsabilidade. Engloba as relações de gênero, o respeito a si mesmo e ao outro e à diversidade de crenças, valores e expressões culturais existentes numa sociedade democrática e pluralista. Inclui a importância da prevenção das doenças sexualmente transmissíveis/ Aids e da gravidez indesejada na adolescência, entre outras questões polêmicas. Pretende contribuir para a superação de tabus e preconceitos ainda arraigados no contexto sociocultural brasileiro (1998)
\end{abstract}

O trabalho pedagógico com esse tema colabora para a prevenção de diversos problemas, como o abuso sexual e a gravidez indesejada. Levantar questões como a gravidez indesejada em debates sobre métodos contraceptivos, levando à reflexão sobre a própria sexualidade e sobre os cuidados necessários para evitá-la. Favorecendo assim, a consciência do cuidado com o corpo. Debates também para prevenir o abuso sexual entre crianças e jovens, contribuindo para o fortalecimento da auto-estima (BRASIL, 1998). 
O trabalho de Orientação Sexual tem como finalidade contribuir para que os alunos possam desenvolver e desempenhar sua sexualidade com responsabilidade. O tema vincula-se à prática da cidadania na medida em que se sugere o desenvolvimento do respeito a si e ao outro e colabora para garantir os direitos básicos a todos como: a saúde, a informação e o conhecimento que são elementos fundamentais para a formação de cidadãos responsáveis e conscientes de suas capacidades (BRASIL, 1998).

A escola sendo capaz de abranger a discussão da sexualidade no seu projeto pedagógico estará se capacitando da interação com os jovens através da linguagem e do foco de interesse que se encontra nessa etapa de suas vidas e que é tão fundamental para a construção de sua identidade (BRASIL, 1998).

O diálogo entre educadores e adolescentes poderá se estabelecer com mais facilidade, contribuindo para que todo o trabalho pedagógico dirija-se melhor. "A presente proposta de trabalho com sexualidade legitima o papel e delimita a atuação do educador neste campo" (BRASIL, 1998).

Portanto esse importante tema deve ser trabalhado em nossas aulas de Matemática através de estatísticas disponíveis nos órgãos oficiais de Saúde da União, do Estado e mesmo dos Municípios. Trabalhar com os dados em forma de tabelas e gráficos, realizando análises e devidas reflexões. Este é um assunto de interesse de todos e importante para uma formação consciente, crítica e saudável dos educandos. (OLIVEIRA, V.D; REIS, S.P.; SILVA, 2009, p.62)

\subsection{MEIO AMBIENTE}

"A medida com que a humanidade aumenta, conseqüentemente aumenta seu poder de intervir na natureza para satisfazer suas necessidades surgindo assim conflitos no que diz respeito ao uso do espaço e dos recursos" (BRASIL, 1998).

Também a industrialização na sua forma de produção, o desenvolvimento, o uso intenso de agrotóxicos, a concentração cada vez maior da população nas cidades, vem aumentando nos últimos séculos. A partir das revoluções industriais e do desenvolvimento, a exploração de recursos naturais vem se intensificando a ponto de pôr em risco a sua renovabilidade, um exemplo básico - a água (BRASIL, 1998).

\footnotetext{
Essas diferenças são definitivas para a degradação do meio. Sistemas inteiros de vida vegetal e animal são tirados de seu equilíbrio. E a riqueza, gerada num modelo econômico que propicia a concentração da renda, não impede o aumento da miséria e da fome. Algumas das conseqüências são, por exemplo, o esgotamento do solo, a contaminação da água e a crescente violência nos centros urbanos (BRASIL, 1997).
} 
Assim, a maior parte da população brasileira faz parte deste tema, a degradação dos ambientes urbanizados, traz como fatores relacionados à fome, violência, baixa qualidade de vida, injustiça social. Problemas estes que vêm confirmar a possibilidade de se manter um ritmo elevado de ocupação, com invasões e destruição da natureza, implicando na vida do planeta. É necessário que haja mudanças de comportamento, para tentar reverter esse quadro (BRASIL, 1998).

A problemática ambiental exige mudanças de comportamentos, de discussão e construção de formas de pensar e agir na relação com a natureza. Isso torna fundamental uma reflexão mais abrangente sobre o processo de aprendizagem daquilo que se sabe ser importante, mas que não se consegue compreender suficientemente só com lógica intelectual. (BRASIL, 1998).

Isso posto, trabalhar com o tema Meio Ambiente tem como função contribuir para a formação de cidadãos conscientes preparados para atuar na realidade socioambiental. Cria-se um comprometimento com a vida e com o bem-estar da sociedade. Com isso, é necessário que a escola se disponha a trabalhar com formação de valores e atitudes, como por exemplo, hábitos de higiene pessoal e gestos de solidariedade com a sociedade são exemplos de aprendizagem que podem acontecer na escola (BRASIL, 1998).

Contribuindo para a formação de cidadãos conscientes, tendo em vista esse tema transversal, a disciplina de matemática pode contribuir através de ferramentas que quantifiquem os aspectos envolvidos em problemas ambientais, possibilitando fazer intervenções necessárias (reciclagem, reaproveitamento de materiais, etc.). Um estudo detalhado sobre questões envolvendo o Meio Ambiente, como poluição, desmatamento, desperdício, camada de ozônio pode ser feito através de conceitos matemáticos como, áreas, volumes, proporcionalidade, interpretação de dados estatísticos, realização de cálculos, etc. Desta maneira se torna possível trabalhar as questões do Meio Ambiente em Matemática (BRASIL, 1998).

Após essas constatações percebemos a importância de desenvolver aspectos que privilegiem a preservação do meio ambiente nas aulas de Matemática, através de dados ambientais coletados em órgãos como Ministério do Meio Ambiente e Secretarias Estaduais e Municipais do Meio ambiente, trabalhados em forma de tabelas e gráficos, destacando a importância de se conservar o meio onde se vive, realizando as devidas analises e reflexões. (OLIVEIRA; REIS; SILVA, 2009, p.65) 


\subsection{SAÚDE}

Sem dúvida alguma, "saúde é o estado de completo bem-estar físico, mental e social e não apenas a ausência de doença" (BRASIL, 1998). Conceito muitas vezes adotado pela Organização Mundial de Saúde (OMS) em 1948, distante de ser uma realidade, representa um compromisso. Transmite a uma idéia de "saúde ótima", provavelmente inatingível e irreal já que a mudança, e não a estabilidade é predominante na vida.

Saúde não é um "estado estável”, que uma vez atingido possa ser mantido. A própria compreensão de saúde tem também alto grau de subjetividade e determinação histórica, na medida em que indivíduos e sociedades consideram ter mais ou menos saúde dependendo do momento, do referencial e dos valores que atribuam a uma situação (BRASIL, 1997).

Inúmeras tentativas vêm sendo realizadas com o intuito de se construir um conceito mais dinâmico, que aborde a saúde não como conceito complementar da doença e sim como construção constante de cada indivíduo e da sociedade (BRASIL, 1998).

Permitindo a compreensão das questões sociais interligadas aos problemas de saúde, as informações e dados estatísticos relacionados com esse tema também favorecem as comparações e previsões que contribuem para o autoconhecimento, favorecendo o cuidado com si próprio e com a sociedade (BRASIL, 1998). Os PCN intensificam quando "A análise dessas situações, tão presentes na vida da maioria dos alunos, é bastante favorável para que eles compreendam a relatividade das medidas estatísticas e de como elas podem ser manipuladas, em função de determinados interesses" (BRASIL,1998).

Após essas reflexões percebemos a importância e a necessidade de se desenvolver nas aulas de matemática temas envolvendo a saúde, pois é um tema de interesse coletivo e que significa até mesmo sobrevivência e bem estar de todos. Trabalhando os dados estatísticos na forma de tabelas e gráficos, buscando dados no Ministério da Saúde, bem como em órgãos Estaduais e Municipais da Saúde, analisando e refletindo sobre os mesmos. (OLIVEIRA; REIS; SILVA, 2009,p.68)

\subsection{PLURALIDADE CULTURAL}

Para se viver numa sociedade plural é necessário respeitar os diversos grupos e culturas que a compõem. A sociedade brasileira é constituída não somente por diversas etnias, mas também por imigrantes de diversos países. Aliás, as migrações colocam em contato grupos diferenciados, levando em consideração que as regiões brasileiras têm características culturais muito diversas e que o convívio entre grupos diversificados nos planos sociais e 
culturais na maioria das vezes é marcado pelo preconceito e pela discriminação (BRASIL, 1998).

\begin{abstract}
A diversidade marca a vida social brasileira. Diferentes características regionais e manifestações de cosmológicas ordenam de maneiras diferenciadas a apreensão do mundo, a organização social nos grupos e regiões, os modos de relação com a natureza, a vivência do sagrado e sua relação com o profano. O campo e a cidade propiciam às suas populações vivências e respostas culturais diversas, que implicam ritmos de vida, ensinamentos de valores e formas de solidariedade distintas. Os processos migratórios colocam em contato grupos sociais com diferenças de fala, de costumes, de valores, de projetos de vida (BRASIL, 1998).
\end{abstract}

Assim, o tema sugere uma compreensão que visa apontar a diversidade étnica e cultural que constitui a sociedade brasileira, entender suas relações traçadas por desigualdades socioeconômicas e assinalar transformações necessárias. Apresentando elementos para a valorização das diferenças étnicas e culturais, levando a respeitá-los como expressão da diversidade, para que não haja qualquer discriminação. Com a afirmativa da diversidade, sendo o traço fundamental na constituição de uma identidade nacional, tendo a Ética como elemento fundamental das relações sociais e interpessoais (BRASIL, 1998).

Abordando a disciplina de Matemática, podemos relacioná-la com a construção e a utilização dos conhecimentos matemáticos que não são feitos apenas por matemáticos, cientistas ou engenheiros entre outros, no entanto, de maneiras diferenciadas, por todos os grupos, que desenvolvem e utilizam habilidades como, contar, localizar, medir, desenhar, representar, entre outros, em função de suas necessidades e interesses (BRASIL, 1998). De acordo com o PCN de Matemática valorizando o saber matemático e ligando-o ao saber escolar em que o aluno está inserido, é possível mostrar ao aluno e possibilitá-lo a participar de levantamentos realizados pelos mesmos e consequentemente despertando seu interesse.

Como a sociedade brasileira possui uma enorme miscigenação de raças e como consequência uma enorme produção cultural é necessário ficarmos atentos aos diversos movimentos culturais e destacá-los em nossas práticas pedagógicas, buscando dados em órgãos oficiais da União, Estados e Municípios acerca deste tema, trabalhando esses dados estatisticamente, em forma de tabelas e gráficos, analisando-os e fazendo as devidas reflexões. (OLIVEIRA; REIS; SILVA, 2009, p.71)

\title{
1.6 TRABALHO E CONSUMO
}

Uma das definições de trabalho é de que este é "a modificação da natureza operada pelos seres humanos de forma a satisfazer suas necessidades. Nessa relação, os homens modificam e interferem nas coisas naturais, transformando-as em produtos do trabalho" (BRASIL apud GROENWALD; BERNDT, 2005, p. 3). 
Também, inúmeras competências podem ser desenvolvidas pelo meio deste tema. De acordo os PCN: "atuar com discernimento e solidariedade nas situações de consumo e de trabalho [...]; identificar a diversidade de relações de trabalho existentes [...]; posicionar-se de maneira crítica em relação ao consumismo [...]" (BRASIL apud GROENWALD; BERNDT, 2005, p.3).

Os seres humanos e as relações que se estabelecem entre si e com a natureza, desenvolvem modos de ser e de viver definindo o que é indispensável para viver bem, sendo bens produzidos pela sociedade, que poderão ser usufruídos.

\begin{abstract}
Materializado nos objetos de consumo, nos produtos e bens materiais ou simbólicos e nos serviços, encontra-se o trabalho humano, realizado sob determinadas relações e condições. As relações existentes entre os homens em sociedade podem ser analisadas a partir das relações de trabalho e consumo, mas ficam muitas vezes obscurecidas pela frequente afirmação de que todos são igualmente livres tanto para trabalhar e escolher um tipo de trabalho como para consumir. Essa afirmação não considera as desigualdades de acesso ao trabalho, aos bens de consumo e aos serviços, ou a distribuição diferenciada entre as classes sociais (BRASIL, 1998)
\end{abstract}

Ao abordar o tema Trabalho e Consumo e interligarmos à Matemática pode-se trabalhar envolvendo algumas situações ligadas ao cotidiano do aluno para serem explorados em sala de aula. Relacionando o estudo de causas que determinam aumento e/ou diminuição de empregos; pesquisa sobre oferta e/ou procura de emprego; previsões sobre o futuro mercado de trabalho em função de indicadores atuais; pesquisas dos alunos dentro da escola ou na comunidade a respeito dos valores que os jovens atribuem ao trabalho. Logo, promovendo a compreensão e a importância dos temas (LIMA, 2008).

Isso posto, destacamos que esses temas são essenciais na formação do cidadão, pois o trabalho e o consumo consciente formará um cidadão crítico e reflexivo para atuar em nossa sociedade., analisando e refletindo sobre dados relativos a esse tema, disponíveis nos órgãos Federais , Estaduais e Municipais. (OLIVEIRA; REIS; SILVA, 2009,p.75)

\title{
1.7 TEMAS LOCAIS
}

Devido ao Brasil ser um país de dimensões continentais salientamos aqui a necessidade dos temas locais serem trabalhados em cada comunidade escolar, privilegiando e destacando as culturas, particularidades e necessidades próprias de cada meio.

Isso nos remete aos PCN( 1998), que nos diz que,

[...] embora os temas transversais foram escolhidos em função das urgências que a sociedade brasileira apresenta, dadas as grandes dimensões do Brasil e as diversas 
realidades que o compõem, é inevitável que determinadas questões ganhem importância maior em uma região.

Isto posto, devemos ficar atentos ao nosso redor, quer seja em temas como a qualidade de vida ou mesmo o trânsito em nossas cidades. Devemos trabalhar esse temas em nossas aulas de matemática buscando dados na Prefeitura ou mesmo nas Associações de Bairros. Trabalhando estatisticamente com esses dados, em forma de tabelas e gráficos, analisando-os e refletindo sobre os mesmos em relação as influências que os mesmos exercem sobre o nosso local de vida.

\section{CONCLUSÃO}

Após essas considerações, pode-se afirmar que a inclusão dos Temas Transversais nas aulas de Matemática é uma maneira de se tratar os temas sociais que estão em evidência e que estão presentes no dia a dia de nossa sociedade.

Assim ao caracterizarmos os Temas Transversais ao longo desse artigo podemos destacar que os mesmos possuem conteúdos referentes a conceitos, procedimentos, valores, normas e atitudes que contribuem para a aquisição das capacidades relacionadas aos objetivos gerais do Ensino. E desenvolver a formação do cidadão para o exercício da cidadania necessita um comprometimento com a adoção de valores e de conhecimentos que permitam desenvolver as ações necessárias para a participação social efetiva. E é justamente nesse ponto que entram os Temas Transversais: Ética, Meio Ambiente, Saúde, Pluralidade Cultural Orientação Sexual, Trabalho e Consumo e Temas Locais. (OLIVEIRA; REIS; SILVA, 2009, p.78).

Isso posto, convém destacar que após essas reflexões com o grupo de alunos da UNIVÁS- OLIVEIRA, V.D; REIS, S.P .; SILVA, C.A.S. de Licenciatura em Matemática Plena da UNIVÁS - Universidade do Vale do Sapucaí, situada em Pouso Alegre- MG, os mesmos sentiram-se motivados a produzirem uma pesquisa intitulada "A Matemática e os Temas Transversais", conforme referência abaixo.

Portanto, façamos uso desses temas como prática pedagógica em nossas aulas de Matemática, para formarmos cidadãos críticos e participativos para exercerem a cidadania em nossa sociedade (DUARTE, 2010, p.36). 


\section{REFERÊNCIAS}

BRASIL, Ministério da Educação e Desporto. Lei de Diretrizes e Bases da Educação Nacional.Brasília:MEC/SEF, 1996.

BRASIL, Ministério da Educação, e do Desporto. Parâmetros Curriculares Nacionais. Brasília: MEC/SEF, 1998.

DUARTE, P. C. X. Desenvolvendo cidadãos atuantes por meio do ensino e aprendizagem da matemática. São Paulo; Porto de Ideias, 2010.

FABRO, Silvia G. V. Discurso matemático na escola: reflexões. Org. Cascavel- Pr:

Unioeste / DME, 1996.

GROENWALD, C. L. O., BERNDT, S. Projeto Matematizando: uma proposta com o Tema Transversal Trabalho e Consumo. Comunicação Científica. Paraná, 2005.

DICINÁRIO HOUAISS DA LÍNGUA PORTUGUESA.Rio de Janeiro: Objetiva, 2009.

IMENES, L. M. P; LELLIS, M. O ensino de matemática e a formação do cidadão. Temas \& Debates. Blumenau, n.5, 1994.

LIMA, C. A. Aproximação entre Ciência- Tecnologia- Sociedade e os temas transversais no livro didático de Matemática do Ensino Fundamental de $5^{\mathrm{a}}$ a $8^{\mathrm{a}}$ séries. Dissertação (Mestrado em Educação Científica e Tecnológica). Universidade Federal de Santa Catarina, Florianópolis, 2008.

OLIVEIRA, V.D; REIS, S.P.; SILVA, C.A.S. Trabalho de Conclusão de Curso (Licenciatura em Matemática): A Matemática e os Temas Transversais. (Minas Gerais: Universidade do Vale do Sapucaí - UNIVÁS, 2009)

PIETROPAOLO, R. C. Parâmetros curriculares de matemática. Educação Matemática em Revista. São Paulo, n. 7, ano 6, p.11-18, jul. 1999.

PRESTINI, S. A. M. M., Transversalidade e Temas Transversais na Formação Inicial do Professor de Matemática. Dissertação (Mestrado em Educação). Universidade Federal do Paraná, Curitiba, 2005.

SEED, Secretaria de Educação do Paraná. Currículo Básico para a Escola Pública do Paraná. 2. ed. Curitiba: Estado, 1992. 
